\title{
Fiscal Policy, Macroeconomic Stability and Finite Horizons*
}

\author{
Javier Andrés ${ }^{a}, \mathrm{R}$. Doménech ${ }^{a}$ and C. Leith ${ }^{b}$ \\ a University of Valencia \\ $b$ University of Glasgow
}

First draft, March 19, 2003.

This version, October 5, 2003.

\begin{abstract}
In this paper we analyse the stabilisation properties of distortionary taxes in a New Keynesian model with overlapping generations of finitely-lived consumers. In this framework, government debt is part of net wealth and this adds a number of interesting channels through which fiscal policy could affect output and inflation. Output volatility, in presence of technology shocks, is not substantially affected by the operation of automatic stabilisers but we find interesting composition effects. While the presence of finitely-lived households strengthens the stabilisation performance of distortionary taxes through the reduction of the volatility of consumption, it does so at the cost of more volatile investment and real balances. These conflicting responses add up to a very small overall welfare losses associated with distortionary taxation.
\end{abstract}

Keywords: Non-Ricardian consumers, macroeconomic stability, distortionary taxes.

JEL Classification: E21, E32, E63.

\section{Introduction}

Until recently, work on the trade-off between output and inflation variability in the context of New Keynesian economies subject to supply shocks has tended to downplay the role of fiscal policy in defining that trade-off (see Clarida et al.,1999, for example). The implicit reasons for ignoring fiscal policy in defining the trade-off are that the economies modelled were typically populated by infinitely-lived economic agents such that, provided the government implemented a "passive" fiscal policy through lump-sum taxation

* Financial support by CICYT grant SEC2002-0026 and EFRD is gratefully acknowledged. Campbell Leith is also grateful to the ESRC grant L138251050 for financial support. Address for comments: J. Andrés and R. Doménech, Dpto. Análisis Económico, Universidad de Valencia, 46022 Valencia, Spain. C: Leith, Department of Economics, Adam Smith Building, University of Glasgow, Glasgow, G12 8RT, UK.e-mail: javier.andres@uv.es, rafael.domenech@uv.es and c.b.leith@socsci.gla.ac.uk. 
(Leeper, 1991) monetary policy was free to minimise the distortions generated by nominal inertia. However, a number of recent papers are now attempting to define the optimal combinations of monetary and fiscal policies in economies where taxation is distortionary (see, for example, Benigno and Woodford, 2003, Benassy, 2003, or Schmitt-Grohé and Uribe, 2002). There has also been some analysis of the impact of fiscal policy on the inflation-output trade-off facing monetary policy makers. For example, Galí (1994) finds, in the context of a real business cycle model, that automatic stabilisers may increase output volatility, while Andrés and Doménech (2003) find that such results can be overturned if the economy is subject to significant real and nominal rigidities.

In the current paper we assess the stabilisation potential of distortionary taxation using a model which departs from previous work in a crucial respect: we relax the assumption of infinitely lived consumers. Specifically, in section 2 we develop a model where overlapping generations of consumers, facing a probability of death, supply labour to imperfectly competitive firms. These firms produce differentiated products using this labour and capital (which is subject to capital adjustment costs). In setting their prices firms are also constrained by Calvo contracts, such that they can only change prices after random intervals of time. There are numerous sources of distortionary taxation in the model: labour income, consumption and profits taxes all affect the decisions made by economic agents within the economy.

The presence of non-Ricardian consumers adds to the canonical model at least two channels that can be relevant for fiscal policy analysis. Firstly, a positive probability of death makes aggregate consumption dynamics dependent on the amount of outstanding debt. Secondly, the steady-state real interest rate increases with the stock of debt. These features are likely to affect the performance of automatic stabilisers since both impinge upon the cyclical response of consumption and investment to technology shocks. Thus, we look at the incidence of distortionary taxation on the components of aggregate demand as well as on leisure and real balances. Furthermore, as a means of obtaining a measure of the overall performance of automatic stabilisers we compute their contribution to (reducing) the welfare cost of technology-driven fluctuations.

A key result of the paper, presented in section 3, is that, relative to an economy without distortionary taxation, introducing distortionary taxes and allowing automatic stabilisers to function, can reduce the volatility of some components of demand, but raise the relative volatility of others. Specifically, in economies with significant deviations from Ricardian consumption behaviour and a large debt/GDP ratio, consumption volatility can be reduced relative to an economy without distortionary taxes, while investment expenditure is more volatile. The reason is that when debt is part of consumers' net wealth the movements in government debt (partially induced by movements in real interest 
rates and therefore debt service costs) serve to offset the impact of real interest rate movements on consumption. In contrast, the higher volatility in real rates that emerge when consumers are not infinitely lived (consumers need greater compensation, cet. par., to hold a given stock of government debt when they are finitely lived) induces greater fluctuations in investment expenditure.

Our welfare analysis, in section 4, suggests that, in general, the welfare cost of fluctuations is higher when distortionary taxes are present and, therefore, the reduction in the relative volatility of consumption does not compensate for the higher volatility of labour and real balances in the economy with distortionary taxes. However, as the wealth effect of government debt increases (either through less Ricardian behaviour on the part of consumers or increases in the steady-state debt to GDP ratio), then the welfare costs of shocks decrease and the difference between a lump-sum and distortionary-taxation financed economy is less marked. Section 5 concludes.

\section{The Model}

\subsection{Capital Rental Firms' Behaviour}

We assume that there is a single representative firm accumulating capital for rental to the intermediate goods firms. ${ }^{2}$ This firm seeks to maximise the discounted value of its cashflows, which are then redistributed to households. Therefore the firm's objective function is to maximise the following expression,

$$
V_{t}=\left(1-\tau_{t}^{k}\right) p_{t}^{k} k_{t}-e_{t}+\sum_{z=1}^{\infty} \frac{\left(\left(1-\tau_{t+z}^{k}\right) p_{t+z}^{k} k_{t+z}-e_{t+z}\right)}{\prod_{j=1}^{z}\left(1+r_{t+j-1}\right)}
$$

where $p_{t}^{k}$ is the real rental cost of capital, $k_{t}$ is the capital stock and $e_{t}$ is real investment expenditure. However, because of capital adjustment costs, only a fraction of investment, $\Phi\left(\frac{e_{t}}{k_{t}}\right) k_{t}$, is actually converted into capital, which also depreciates at rate $\delta$. Therefore the equation of motion of the capital stock is given by,

$$
k_{t+1}=\Phi\left(\frac{e_{t}}{k_{t}}\right) k_{t}+(1-\delta) k_{t}
$$

2 The model solution as well as the log-linearized system describing the dynamics are contained in a technical appendix available at http://iei.uv.es/ rdomenec/ADL/tech_appendix.pdf. 
The Lagrangian associated with this problem is given by,

$$
\begin{aligned}
L_{t}= & \left(1-\tau_{t}^{k}\right) p_{t}^{k} k_{t}-e_{t}+\lambda_{t}^{k}\left(\Phi\left(\frac{e_{t}}{k_{t}}\right) k_{t}+(1-\delta) k_{t}-k_{t+1}\right) \\
& +\sum_{z=1}^{\infty}\left[\begin{array}{c}
\frac{\left(1-\tau_{t+z}^{k}\right)\left(p_{t+z}^{k} k_{t+z}-e_{t+z}\right)}{\prod_{j=1}^{z}\left(1+r_{t+j-1}\right)}+\lambda_{t+z}^{k}\left(\Phi\left(\frac{e_{t+z}}{k_{t+z}}\right) k_{t+z}\right. \\
\left.+(1-\delta) k_{t+z}-k_{t+z+1}\right)
\end{array}\right]
\end{aligned}
$$

Therefore, the first order condition for investment is given by,

$$
\lambda_{t}^{k} \Phi^{\prime}\left(\frac{e_{t}}{k_{t}}\right)=1
$$

where $\lambda_{t}^{k}$ is the Lagrange multiplier associated with the equation of motion for the capital stock. Also, differentiating the Lagrangian with respect to $k_{t+1}$ gives the equation of motion for Tobin's $q$,

$$
\lambda_{t}^{k}=\frac{\left(1-\tau_{t+1}^{k}\right) p_{t+1}^{k}}{1+r_{t}}+\left(\Phi\left(\frac{e_{t+1}}{k_{t+1}}\right)-\Phi^{\prime}\left(\frac{e_{t+1}}{k_{t+1}}\right) \frac{e_{t+1}}{k_{t+1}}+(1-\delta)\right) \frac{\lambda_{t+1}^{k}}{1+r_{t}}
$$

\subsection{Price Setting: Nominal Inertia}

If firms cannot change prices in every period then there is not a symmetric equilibrium in which $P_{i t}=P_{t}$. Instead, to facilitate aggregation, we follow Calvo's model of nominal inertia (see Calvo, 1983): a percentage $\phi$ of firms set

$$
P_{i t}=\bar{\pi} P_{i t-1}
$$

whereas the rest of the firms $(1-\phi)$ select $\widetilde{P}_{i t}$ to maximize the value of their shares, that is, the present discount value of future profits:

$$
\begin{aligned}
& \max _{\widetilde{P}_{i t}}\left\{\widetilde{P}_{i t} y_{i t}-P_{t} m c_{t}\left(y_{i t}+\kappa\right)+\right. \\
& \left.E_{t} \sum_{j=1}^{\infty} \frac{\phi^{j}}{\prod_{s=0}^{j}\left(1+i_{t+s}\right)}\left[\widetilde{P}_{i t} \bar{\pi}^{j} y_{i t+j}-P_{t+j} m c_{t+j}\left(y_{i t+j}+\kappa\right)\right]\right\}
\end{aligned}
$$

subject to the demand curve implied by the CES-form of the consumption basket defined above,

$$
y_{i t+j}=\left(\widetilde{P}_{i t} \bar{\pi}\right)^{-\varepsilon} P_{t+j}^{\varepsilon} y_{t+j}
$$

and where the production function is given by: 


$$
y_{i t}=A k_{i t}^{\alpha} l_{i t}^{1-\alpha}\left(g_{t}^{p}\right)^{\theta}-\kappa
$$

The first order condition is,

$$
\widetilde{P}_{i t}=\left(\frac{\varepsilon}{\varepsilon-1}\right) \frac{P_{t}^{\varepsilon+1} m c_{t} y_{t}+E_{t} \sum_{j=1}^{\infty}\left[\frac{\phi^{j} P_{t+j}^{\varepsilon+1} m c_{t+j} y_{t+j} \bar{\pi}^{-j \varepsilon}}{\prod_{s=1}^{j}\left(1+i_{t+s}\right)}\right]}{P_{t}^{\varepsilon} y_{t}+E_{t} \sum_{j=1}^{\infty}\left[\frac{\phi^{j} P_{t+j}^{\varepsilon} y_{t+j} \bar{\pi}^{j(1-\varepsilon)}}{\prod_{s=1}^{j}\left(1+i_{t+s}\right)}\right]}
$$

and the aggregate price index at $t$ is,

$$
P_{t}=\left[\phi\left(\bar{\pi} P_{t-1}\right)^{1-\varepsilon}+(1-\phi) \widetilde{P}_{t}^{1-\varepsilon}\right]^{\frac{1}{1-\varepsilon}}
$$

\subsection{Capital and Labour Demand: Cost Minimization.}

Once prices are set, demand is given by the downward sloping curve that each firm faces. The optimal combination of capital and labour is obtained from the cost minimization problem of the firm:

$$
\begin{gathered}
w_{t}=m c_{t}(1-\alpha) A k_{t}^{\alpha} l_{t}^{\alpha}\left(g_{t}^{p}\right)^{\theta} \\
r_{t}=m c_{t} \alpha A k_{t}^{\alpha-1} l_{t}^{1-\alpha}\left(g_{t}^{p}\right)^{\theta}
\end{gathered}
$$

where,

$$
m c_{t}=\left(\frac{r_{t}}{\alpha}\right)^{\alpha}\left(\frac{w_{t}}{1-\alpha}\right)^{1-\alpha}
$$

\subsection{Consumers' Behaviour}

Here we introduce the main departure from the canonical new-Keynesian model. While there is abundant evidence of a strong interaction among fiscal impulses and output (see, for example, Blanchard and Perotti, 2002, or Fatas and Mihov, 1998), standard dynamic general equilibrium models downplay the role of demand. The importance of the demand side of the economy is partially restored when there is slow adjustment in nominal and real variables, but still intertemporal substitution mechanisms and Ricardian equivalence leave consumption largely unresponsive to a fiscal stimulus. Introducing a probability of death implies that consumers discount their future disposable income more heavily, such that the the usual Ricardian experiment of a deficit-financed tax cut now increases 
consumption. Let us describe in detail the environment in which households' decisions take place.

A consumer born at time $t-i$, receives utility from consuming a basket of consumer goods,

$$
c_{t}^{i}=\left[\int_{0}^{1} c_{t}^{i}(z)^{\frac{\epsilon-1}{\epsilon}} d z\right]^{\frac{\epsilon}{\epsilon-1}},
$$

holding real money balances, $M_{t}^{i} / P_{t}$ and suffers disutility from supplying labour to imperfectly competitive firms, $l_{t}^{i}$,

$$
E_{t} U=E_{t} \sum_{z=0}^{\infty} \beta^{z}\left(\ln c_{t+z}^{i}+\chi \ln \frac{M_{t+z}^{i}}{P_{t+z}}+\varkappa \ln \left(1-l_{t+s}^{i}\right)\right.
$$

There are two sources of uncertainty in the model: consumers face a constant probability of death $(1-\gamma)$, and the firms that employ them can only set their prices at stochastic intervals. These sources of individual uncertainty can all be pooled so that there is no aggregate uncertainty. Therefore the individual's certainty equivalent utility function is given by,

$$
E_{t} U=\sum_{z=0}^{\infty}(\gamma \beta)^{z}\left(\ln c_{t+z}^{i}+\chi \ln \frac{M_{t+z}^{i}}{P_{t+z}}+\varkappa \ln \left(1-l_{t+z}^{i}\right)\right.
$$

Consumers seek to maximise utility subject to the demand schedule for their labour services and their budget constraint, which in nominal terms can be written as

$$
\begin{aligned}
& \gamma M_{t}^{i}+\frac{\gamma B_{t}^{i}}{1+i_{t}}+P_{t}\left(1+\tau_{t}^{c}\right) c_{t}^{i} \\
= & P_{t}\left(1-\tau_{t}^{w}\right) w_{t} l_{t}^{i}+B_{t-1}^{i}+M_{t-1}^{i}+P_{t} s_{t}^{i}+\left(1-\tau_{t}^{k}\right)\left(\int_{0}^{1} \Omega_{t}^{j} d j+\Omega_{t}^{k}\right)
\end{aligned}
$$

Here consumers earn after tax income from their labour services $P_{t}\left(1-\tau_{t}^{w}\right) w_{t} l_{t}^{i}$, receive their share of the profits of intermediate goods producers, $\left(1-\tau_{t}^{k}\right) \int_{0}^{1} \Omega_{t}^{j} d j$ and capital rental companies $\frac{\Omega_{t}^{k}}{P_{t}}$ and public transfers, $P_{t} s_{t}$. Households also hold their assets in two forms: money, $M_{t}^{i}$, and government bonds, $B_{t}^{i}$. Money pays no interest, while bonds earn interest at the rate $i_{t}$. It would be possible for consumers to invest in a portfolio of equity holdings of intermediate goods firms and capital rental firms - in the case of the intermediate goods producers this would also diversify the risk due to staggered price setting and would affect the distribution of profits across consumers at different stages in their life cycle. However, in aggregate, this does not matter, so, for simplicity, we 
assume a simple lump-sum redistribution of aggregate profits. The gross nominal rate of return on financial assets is given by $1+i_{t}$, and competitive insurance companies contract with individuals to receive their financial wealth should they die in return for a insurance premium equal to the probability of death -this raises the effective rate of interest to $\frac{1+i_{t}}{\gamma}$. We can therefore, rewrite the individual's flow budget constraint in real terms as,

$$
\begin{aligned}
& \gamma m_{t}^{i}+\frac{\gamma b_{t}^{i}}{1+i_{t}}+\left(1+\tau_{t}^{c}\right) c_{t}^{i} \\
= & \left(1-\tau_{t}^{w}\right) w_{t} l_{t}^{i}+\frac{b_{t-1}^{i}+m_{t-1}^{i}}{\pi_{t}}+s_{t}^{i}+\left(1-\tau_{t}^{k}\right) \int_{0}^{1}\left(\frac{\Omega_{t}^{j}}{P_{t}} d j+\frac{\Omega_{t}^{k}}{P_{t}}\right)
\end{aligned}
$$

where $\pi_{t} \equiv P_{t} / P_{t-1}$

Let us define

$$
\begin{gathered}
\Omega_{t}^{i} \equiv \int_{0}^{1}\left(\frac{\Omega_{t}^{j}}{P_{t}} d j+\frac{\Omega_{t}^{k}}{P_{t}}\right) \\
H_{t}^{i} \equiv\left(\left(1-\tau_{t}^{w}\right) w_{t} l_{t}^{i}+s_{t}^{i}+\left(1-\tau_{t}^{k}\right) \Omega_{t}^{i}\right)
\end{gathered}
$$

and

$$
\Lambda_{t}^{i} \equiv H_{t}^{i}-\left(1+\tau_{t}^{c}\right) c_{t}^{i}-\frac{i_{t-1}}{\pi_{t}} m_{t-1}^{i}
$$

Then, the budget constraint can be written as

$$
b_{t-1}^{i}+\left(1+i_{t-1}\right) m_{t-1}^{i}=-\pi_{t} \Lambda_{t}^{i}+\frac{\gamma \pi_{t}}{1+i_{t}}\left[m_{t}^{i}\left(1+i_{t}\right)+b_{t}^{i}\right]
$$

Integrating the flow budget constraint forwards and imposing the no-Ponzi Game condition yields the consumer's intertemporal budget constraint,

$$
b_{t-1}^{i}+\left(1+i_{t-1}\right) m_{t-1}^{i}=-\pi_{t} \Lambda_{t}^{i}-\pi_{t} \sum_{z=1}^{\infty} \frac{\gamma^{z} \Lambda_{t+z}^{i}}{\prod_{j=1}^{z}\left(1+r_{t+j-1}\right)}
$$

where $1+r_{t} \equiv\left(1+i_{t}\right) / \pi_{t+1}$ is the ex post real rate of return on financial assets.

Maximising utility subject to this intertemporal budget constraint yields the following first order conditions. Firstly for consumption,

$$
\left(1+\tau_{t+z}^{c}\right) c_{t+z}^{i}=\beta^{z} \frac{1}{\lambda_{t}^{i}} \prod_{j=1}^{z}\left(1+r_{t+j-1}\right)
$$


where $\lambda_{i}$ is the Langrange multiplier associated with the intertemporal budget constraint in the consumer's optimisation. This expression can be used to derive the individual consumer's consumption Euler equation,

$$
\left(1+\tau_{t+z}^{c}\right) c_{t+z}^{i}=\beta^{z}\left(1+\tau_{t}^{c}\right) c_{t}^{i} \prod_{j=1}^{z}\left(1+r_{t+j-1}\right)
$$

There is also a first-order condition for the holding of money balances,

$$
m_{t+z}^{i}=\frac{\chi}{\gamma} \frac{1+i_{t+z}}{i_{t+z}}\left(1+\tau_{t+z}^{c}\right) c_{t+z}^{i}
$$

and for labour supply,

$$
\left(1-\tau_{t+z}^{w}\right) w_{t+z}\left(1-l_{t+z}^{i}\right)=\varkappa\left(1+\tau_{t+z}^{c}\right) c_{t+z}^{i}
$$

Using the money-demand equation and the Euler equation we can obtain the consumer's consumption function,

$$
\left(1+\tau_{t}^{c}\right) c_{t}^{i}=\frac{1-\gamma \beta}{1+\chi(\gamma \beta)^{-1}}\left[\frac{b_{t-1}^{i}+\left(1+i_{t-1}\right) m_{t-1}^{i}}{\pi_{t}}+H_{t}^{i}+\sum_{z=1}^{\infty} \frac{\gamma^{z} H_{t+z}^{i}}{\prod_{j=1}^{z}\left(1+r_{t+j-1}\right)}\right]
$$

\subsection{Aggregating across Consumers and Consumption Dynamics.}

If the size of each cohort when born is 1 , then the size of a cohort of age $i$ is given by, $\gamma^{i}$. Therefore the total size of the population is given by,

$$
\sum_{s=1}^{\infty} \gamma^{i-1}=\frac{1}{1-\gamma}
$$

It is therefore possible to aggregate across consumers different generations to generate an aggregate per capita consumption function,

$$
\left(1+\tau_{t}^{c}\right) c_{t}=\frac{1-\gamma \beta}{1+\chi(\gamma \beta)^{-1}}\left[\frac{b_{t-1}+\left(1+i_{t-1}\right) m_{t-1}}{\pi_{t}}+l w_{t}\right]
$$

where

$$
l w_{t} \equiv H_{t}+\sum_{z=1}^{\infty} \frac{\gamma^{z} H_{t+z}}{\prod_{j=1}^{z}\left(1+r_{t+j-1}\right)}
$$


In this simple closed economy model net financial assets will correspond with government debt.

Aggregating consumers' labour supply yields,

$$
\left(1-\tau_{t}^{w}\right) w_{t}\left(1-l_{t}\right)=\varkappa\left(1+\tau_{t}^{c}\right) c_{t}
$$

and the aggregate demand for money is given by,

$$
m_{t}=\frac{\chi}{\gamma} \frac{1+i_{t}}{i_{t}}\left(1+\tau_{t}^{c}\right) c_{t}
$$

where all variables are now in per capita terms.

Finally, from the aggregate consumption function and using the government budget constraint, after some algebra (see the Appendix) we obtain the dynamics for aggregate consumption in the presence of Ricardian consumers,

$$
\begin{aligned}
\left(1+\tau_{t+1}^{c}\right) c_{t+1}= & \frac{1-\gamma \beta}{1+\chi(\gamma \beta)^{-1}}\left\{\frac{\left(1+r_{t}\right) \beta\left(1+\chi(\gamma \beta)^{-1}\right)\left(1+\tau_{t}^{c}\right) c_{t}}{(1-\gamma \beta)}+\right. \\
& \left.+\frac{(\gamma-1)\left(1+r_{t}\right)}{\gamma}\left[m_{t}+\frac{b_{t}}{1+i_{t}}\right]\right\}
\end{aligned}
$$

This expression summarizes the two main changes that a model with finitely-lived agents opens up for fiscal policy. For one thing, when consumers have finite lives, $\gamma<1$, Ricardian equivalence breaks down and government debt affects the path of aggregate consumption. Additionally, since non-Ricardian consumers require a higher real interest rates to be prepapred to hold higher levels of government debt, cet par, fluctuations in government debt also affect the real interest rate in general equilibrium thereby influencing the cyclical response of consumption, investment and hours to technology shocks.

\subsection{Monetary and Fiscal Policy}

Monetary and fiscal policy is modeled as in Andrés and Doménech (2003). In particular, monetary policy is represented by a standard Taylor rule:

$$
i_{t}=\rho_{r} i_{t-1}+\left(1-\rho_{r}\right) \bar{i}+\left(1-\rho_{r}\right) \rho_{\pi}\left(\pi_{t}-\bar{\pi}\right)+\left(1-\rho_{r}\right) \rho_{y} \widehat{y}_{t}+z_{t}^{i}
$$

in which the monetary authority sets the interest rate $\left(i_{t}\right)$ to prevent inflation deviating from its steady-state level $\left(\pi_{t}-\bar{\pi}\right)$ and to counteract movements in the output gap $\left(\widehat{y}_{t}\right)$; $\bar{i}$ is the steady-state interest rate and the current rate moves smoothly $\left(0<\rho_{r}<1\right)$ and has an unexpected component, $z_{t}^{i}$.

Provided that $\rho_{\pi}$ is above a certain threshold value, fiscal policy must be designed to satisfy the present value budget constraint of the public sector for any price level in 
order to obtain a unique monetary equilibrium (Leeper, 1991, Woodford, 1996, Leith and Wren-Lewis, 2000). A simple way of making this requirement operational is to assume that either taxes or public spending respond sufficiently to the level of debt. We use fiscal rules in which the deviation of each component of public spending (consumption $\left(g_{t}^{c}\right)$, investment $\left(g_{t}^{p}\right)$ and/or transfers $\left.\left(g_{t}^{s}\right)\right)$ from its steady-state value is a function of the deviation of the debt to output ratio from its target:

$$
\frac{g_{t}}{\bar{g}}=\left(\frac{b_{t-j}}{y_{t-j}} \frac{\bar{y}}{\bar{b}}\right)^{-\alpha_{b}}\left(\frac{y_{t}}{\bar{y}}\right)^{-\alpha_{y}}, \quad \alpha_{b}, \alpha_{y} \geq 0
$$

where the bar over the variables indicates steady-state values.

\subsection{Calibration}

In order to analyse the main implications of our model, we have obtained a numerical solution of the steady state as well as of the log-linearized system. Table 1 summarizes the values of the calibrated baseline parameters. Most of them are taken from Andrés and Doménech (2003) and are similar to other DGE models as, for example, the parameters of the production function, the Taylor rule or the Phillips curve. However, since some parameters are specific to our model, they should be calibrated. Thus, $\chi$ has been chosen to match the ratio of M1 to quarterly GDP in EMU, using data from 2002, when this ratio was 1.37. Parameter $\varkappa$ was set to 1.28 since we assume that in the steady state households allocate 0.31 of their time to market activities, as in Cooley and Prescott (1995). Under the assumption that the consolidation of public debt to the target $b / y=2.4$ (i.e., a annual debt to GDP ratio of 60 per cent) is made only through transfers $\left(\alpha_{b}^{s}=0.15\right.$ and $\alpha_{b}^{c}=\alpha_{b}^{p}=$ 0.0 ) and that $\gamma=0.995$ (implying an expected adult life of 50 years), the simulated model reproduces the most salient facts of European business cycles which appear in Table 2 as, for example, the relative volatility of consumption $\left(\sigma_{c} / \sigma_{y}\right)$, investment $\left(\sigma_{e} / \sigma_{y}\right)$ or correlation between the primary budget surplus and output $\left(\sigma_{p b s, y}\right)$. The model also yields close values of the private consumption and investment to GDP ratios in steady state to the average values observed in EMU from 1960 to $1999 .^{3}$

The model with supply shocks has been simulated 100 times, producing $200 \mathrm{ob}-$ servations. We take the last 100 observations and compute the steady-sate value $(\bar{x})$, the relative standard deviation to output $\left(\sigma_{x} / \sigma_{y}\right.$, except for GDP which is just $\left.\sigma_{y}\right)$, the first-order autocorrelation $\left(\rho_{x}\right)$ and the contemporaneous correlation with output $\left(\rho_{x y}\right)$ of each variable. We have also simulated an economy with zero tax rates on consump-

3 Standard deviations have been taken from Agresti and Mojon (2001), using the HP filter. Consumption and investment shares have been calculated using OECD Economic Outlook annual data from 1960 to 1999. Finally, the cross correlation of the primary budget surplus and output refers to EMU from 1970 to 2001. 
Table 1

Calibration of baseline model

\begin{tabular}{cccccccccccc}
\hline \hline$\chi$ & $\beta$ & $\gamma$ & $\alpha$ & $\theta$ & $\delta$ & $\sigma_{z}$ & $\rho_{z}$ & $\varepsilon$ & $\kappa$ & $\Theta$ & $\phi$ \\
0.0285 & 0.9926 & 0.995 & 0.40 & 0.10 & 0.021 & 0.874 & 0.80 & 6.0 & 0.20 & -0.25 & 0.75 \\
\hline$\tau^{w}$ & $\tau^{k}$ & $\tau^{c}$ & $g^{c} / y$ & $g^{s} / y$ & $g^{p} / y$ & $\alpha_{b}^{c}, \alpha_{b}^{p}$ & $\alpha_{b}^{s}$ & $\rho_{r}$ & $\rho_{\pi}$ & $\pi$ & $\varkappa$ \\
0.439 & 0.21 & 0.14 & 0.18 & 0.16 & 0.06 & 0.00 & 0.15 & 0.5 & 2.0 & $1.02^{0.25}$ & 1.28 \\
\hline \hline
\end{tabular}

tion, labour and capital incomes, in which public spending is financed using a lump-sum tax such that $\bar{g}^{s} / \bar{y}=-0.26$, but with otherwise identical fiscal structure as that in the benchmark model $\left(\bar{g}^{c} / \bar{y}=0.18, \bar{g}^{p} / \bar{y}=0.06, \bar{b} / \bar{y}=0.6\right)$

We shall see below that output volatility is sensitive to the fiscal instrument used to stabilise debt, the level of debt and the extent to which consumers discount the future more heavily due to finite lives. Indeed the sensitivity of this result to these factors stems from the fact that the introduction of finite lives consumers has very different impacts on key components of aggregate demand. The volatility of consumption relative to output will tend to be less in the non-lump-sum economy, while the volatility of investment will be higher. The reason for this is that, in the presence of finite lives, the wealth effect of government debt on consumption will tend to offset the effect of any movements in real interest rates induced by changes in the outstanding stock of government liabilities. With no such finite horizon effect operating on investment, the response of investment to changes in interest rates is that much stronger.

\section{Finite Horizons, Debt and Output Volatility}

In this section we use the model in section 2 to assess the contribution to macroeconomic stability of distortionary taxes. The statistic used to summarize our result is relative output volatility, which is defined as the standard deviation of output in the economy with distortionary taxes $\left(\sigma_{y}^{d}\right)$ relative to the standard deviation in the economy with lump-sum taxes $\left(\sigma_{y}^{l}\right)$. In particular a ratio below one implies that distortionary taxes are functioning as automatic stabilisers, in particular dampening the movements of disposable income in response to technology shocks. Although it may seem natural for distortionary taxes to have this effect Galí (1994) demonstrates, in the context of a real business cycle model, that income taxes actually tend to magnify output volatility as compared with lump-sum ones. The explanation of such a result can be found in the destabilizing effect that distortionary taxes generate in the use of productive factors, with a reduction of the steady state value of capital and labour, thus magnifying the relative size of cyclical fluctuations. Indeed, the RBC version of our model $\left(\Phi\left(\frac{e}{k}\right)=\frac{e}{k}, \phi=0, \gamma=1\right)$ reproduces that result with a ratio $\sigma_{y}^{d} / \sigma_{y}^{l}=1.2$. Andrés and Doménech (2003) have shown that this ra- 
Table 2

Comparison of EMU and model data

\begin{tabular}{lcc}
\hline \hline & EMU & Model \\
\hline$\sigma_{y}$ & 1.0 & 1.0 \\
$\sigma_{c} / \sigma_{y}$ & 0.7 & 0.8 \\
$\sigma_{e} / \sigma_{y}$ & 2.2 & 2.5 \\
$\sigma_{p b s, y}$ & 0.71 & 0.73 \\
$c / y$ & 0.55 & 0.53 \\
$e / y$ & 0.23 & 0.23 \\
& & \\
\hline \hline
\end{tabular}

tio is diminished in economies with substantial nominal and real frictions; the rationale for this is that those frictions give a more important role to developments on the demand side of the economy. When taxes are linked to consumption and income, countercyclical movements on the aggregate demand interact with those on the supply side, helping to mitigate the volatility of output. Our model under $\gamma=1$ reproduces that result since $\sigma_{y}^{d} / \sigma_{y}^{l}=0.93 .^{4}$

The aim of this section is to focus on the new dimension of the model introduced by allowing consumers to behave in a non-Ricardian manner. In particular, we analyse how the cyclical properties of the main variables are affected by the value of the survival probability $(\gamma)$ and the debt to output ratio $(B / Y)$. Strictly speaking only the value of $\gamma$ characterises the extent of non-Ricardian behaviour. Nevertheless, for non-zero probability of death the steady-state stock of outstanding debt matters both because of its direct effect on consumption and also because it influences the steady-state real rate of interest. To isolate the effects of these changes in $\gamma$ and in $B / Y$ we consider a fiscal rule only in transfers (i.e., $\alpha_{b}^{c}=\alpha_{b}^{p}=0$ ), since the consolidation of public debt through public consumption and/or investment may induce additional demand and supply impacts.

The first result to notice is summarized in Figure 1. Somewhat strikingly, relative output volatility $\left(\sigma_{y}^{d} / \sigma_{y}^{l}\right)$ seems to be immune to changes in either these two parameters. Except for very low values of $\gamma$ and high $B / Y$ both tax structures generate a similar volatility of output, although distortionary taxes seem to perform slightly better: relative output volatility is lower than one. This unchanged ratio is the result of a common pattern associated with both tax structures: as the non-Ricardian friction becomes larger, the volatility of output decreases.

A closer look at the response of aggregate demand components reveals significant

4 The correpsonding ratios for the volatitlity of private consumption are $\left(\sigma_{c}^{d} / \sigma_{c}^{l}\right)_{\text {Gali }}=1.24$ and $\left(\sigma_{c}^{d} / \sigma_{c}^{l}\right)_{A \& D}=1.05$ 


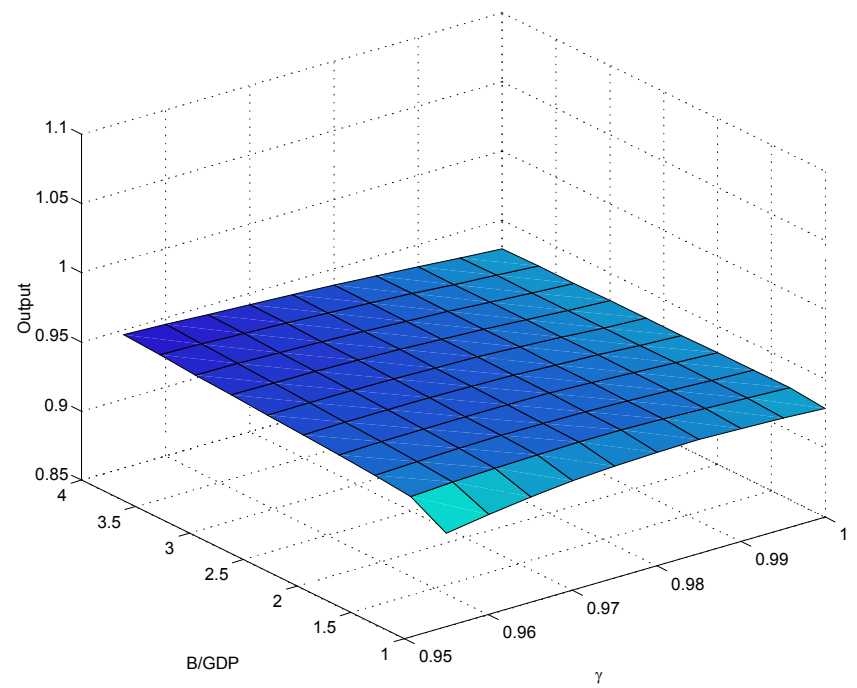

Figure 1: Relative volatility of output as a function of $\gamma$ and $B / G D P$.

differences across them implying automatic stabilizers may have a far greater impact than that measured by relative output volatility. This can be seen in Figure 2 which represents how the relative volatility of the main variables varies across $\gamma$ and $B / Y$. The first thing to notice is that the relative volatility of investment, hours and real balances is always greater than one, and so is that of private consumption for low values of the debt to GDP ratios. This is not inconsistent with relative output volatility being less than one and merely reflects a composition effect since the steady-state level of investment is much greater in an economy without distortionary taxation. ${ }^{5}$ What is more remarkable though is the divergent patterns that emerge as we depart from the world of Ricardian consumers. As the debt to GDP ratio increases and $\gamma$ falls, the relative volatility of investment rises sharply, even in the presence of significant capital adjustment costs.

The reason for this can be seen in Figure 3 which reveals that the steady-state interest rate level is much higher for low $\gamma$ and high $B / Y$, leading to a lower demand for capital and, thus, to larger relative fluctuations in investment under distortionary taxes. Hours worked are also affected in the same manner, since lower steady-state

5 Since the fiscal rule operates only through transfers, public consumption and investment are constant, implying that their variances and covariances are zero. Figure 2 shows that for low values of $b / y \sigma(c)^{l}<\sigma(c)^{d}<\sigma(e)^{l}<\sigma(e)^{d}$. Since the covariance between private consumption and investment are also higher in the economy with distortionary taxes, only the composition effect can explain that $\sigma(y)^{d}<\sigma(y)^{l}$. We have checked that this is the case since the private investment share is much larger in the economy with lump-sum taxes than in the economy with distortionary capital income taxes, which also suffers from a lower $k / y$. 

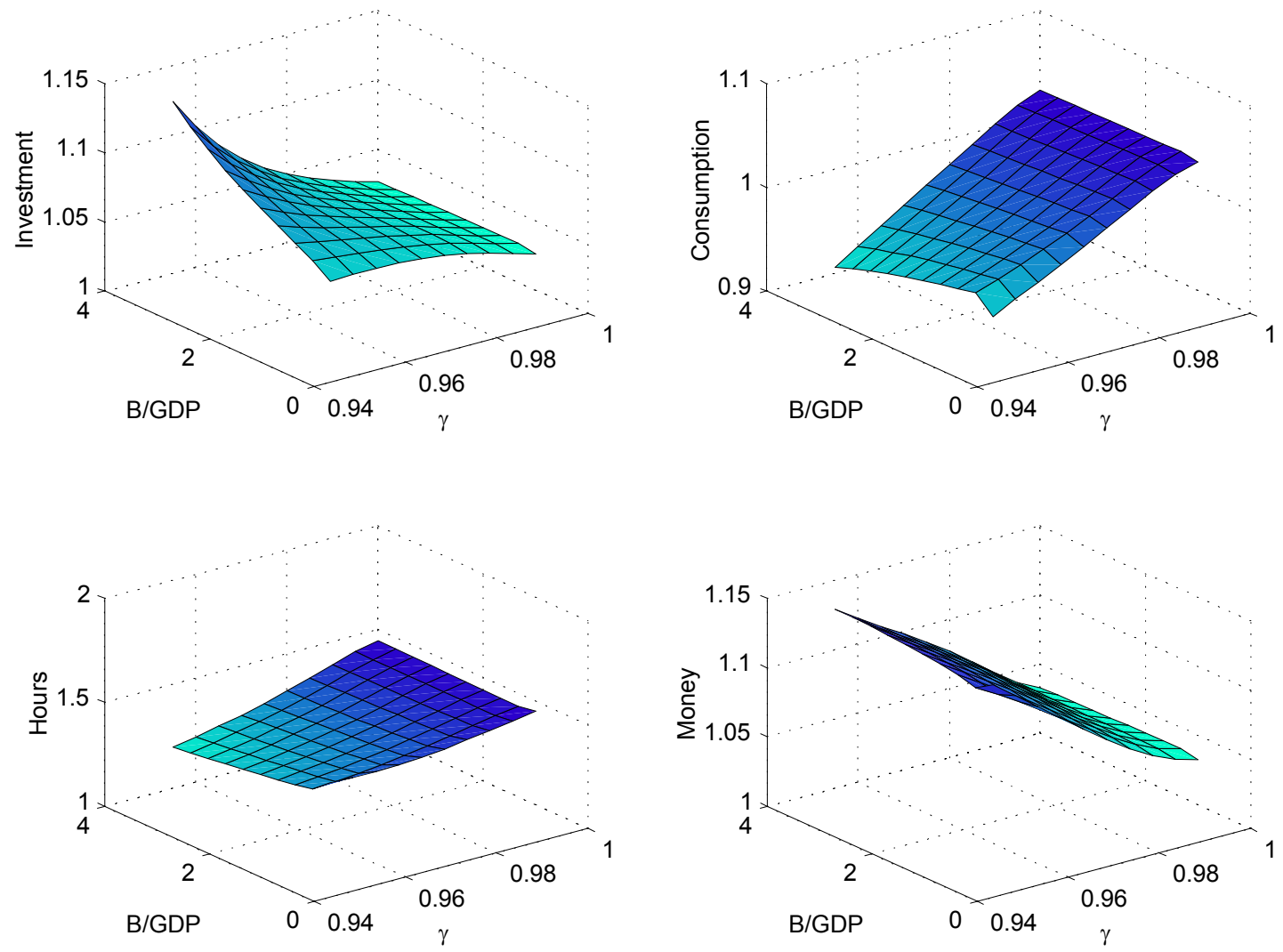

Figure 2: Relative volatility of investment, consumption, hours and output as a function of $\gamma$ and $B / G D P$.

capital means less hours worked and hence stronger cyclical fluctuations.

These steady-state values have the opposite effect on consumption. As $\gamma$ falls the variance of consumption increases in both economies. This is consistent with the Euler equation for consumption, because now the volatility of consumption is affected by the volatility of wealth, as expression (35) makes clear. When $\gamma=0$ consumption is affected only by the expected path of real interest rates, but $\gamma<0$ means that consumers are more aware of changes in their current real wealth. However, the increase in the volatility of consumption is more pronounced in the economy with lump-sum taxes, a result which can be explained by the fact that the coefficient of the changes in real wealth in the dynamic version of the Euler equation is a negative funtion of $\tau_{c}$ and the ratio of private consumption to GDP in the steady state. Since both $\tau_{c}$ and $\bar{c} / \bar{y}$ are higher in the economy 


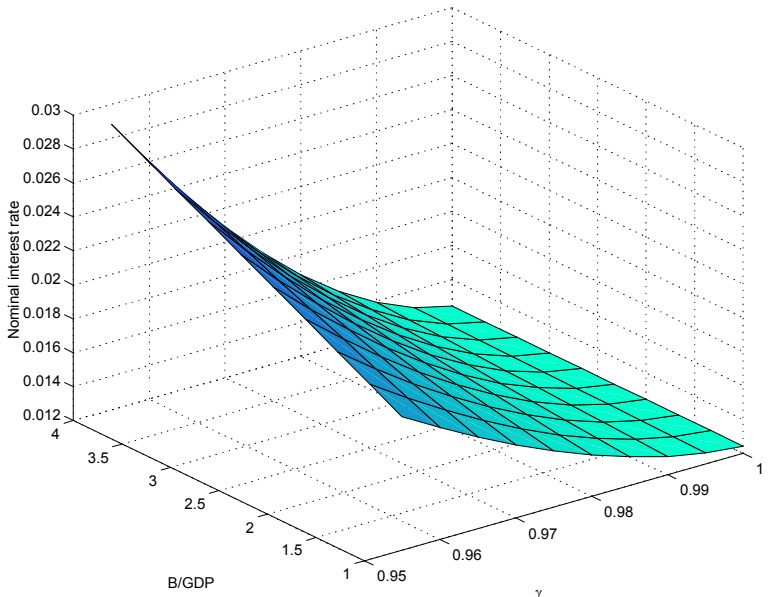

Figure 3: Real interest rate in the steady state as a function of $\gamma$ and $B / G D P$.

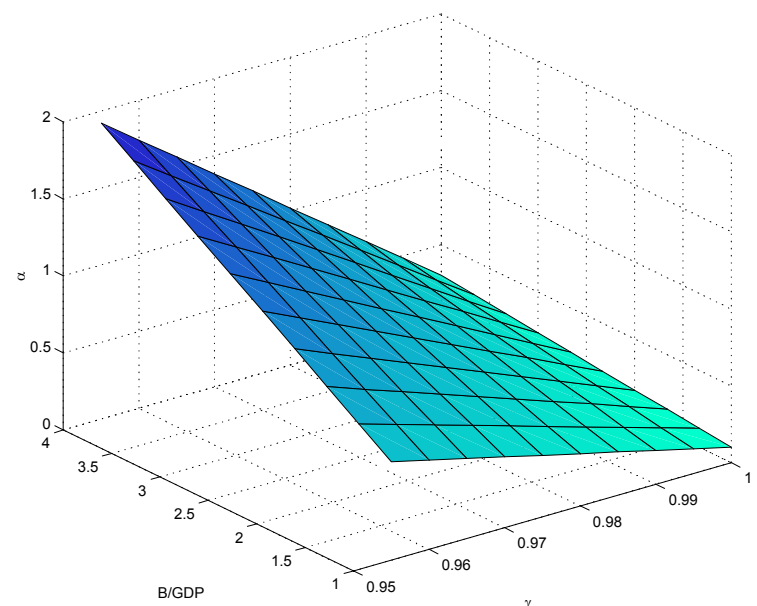

Figure 4: Minimun values of $\alpha_{b}^{s}$ required for being in a regime with pasive fiscal policy as a function of $\alpha_{y}^{s}$ and $B / Y$. 
with distortionary taxation, it follows that the increase of the variance of consumption is higher in the economy with lump-sum taxes.

The volatility of consumption, is also affected by another interesting feature of the non-Ricardian model. As the survival rate falls the elasticity of transfers to the debt to GDP ratio ( $\alpha^{b}$ in the fiscal rule) needed to ensure a unique monetary equilibrium increases. This increase is much larger as the steady state $B / Y$ rises as Figure 4 shows. High (low) debt (survival rate) is associated with high interest payments so that the fiscal rule must be more aggressive in preventing deviations of the debt to GDP ratio from target. Otherwise, following shocks, significant changes in the level of debt may prevent convergence to the steady state. However, as the aggressiveness of the fiscal rule is increased the ability of debt to reduce the volatiltity of consumption is reduced. ${ }^{6}$

\section{The Welfare Costs of Fluctuations}

Given that the relative volatility of many macroeconomic aggregates varies in opposite directions when the survival rate or the debt to output ratio changes, we need an appropriate metric to asses which situation among the different alternatives has grater impact on households' welfare. In principle, the survival rate is exogenous in our model but different levels of the debt to output ratio can be targeted. The natural solution to this problem is to compare the expected utility of a representative agent in economies with distortionary and lump-sum taxes with the expected utility in their respective steady states. To do so we compute the proportional reduction in private consumption $(\psi)$ in steady state needed to make an average consumer indifferent between being permanently in the steady state or in an economy subject to technology shocks:

$$
\begin{aligned}
0= & \sum_{z=0}^{\infty}(\gamma \beta)^{z}\left\{\ln (1-\psi) \bar{c}_{t+z}+\chi \ln \frac{\bar{M}_{t+z}}{\bar{P}_{t+z}}+\varkappa \ln \left(1-\bar{l}_{t+z}\right)\right\} \\
& -\sum_{z=0}^{\infty}(\gamma \beta)^{z}\left\{\ln c_{t+z}+\chi \ln \frac{M_{t+z}}{P_{t+z}}+\varkappa \ln \left(1-l_{t+z}\right)\right\}
\end{aligned}
$$

such that $\bar{c}_{t+z}$ refers to the steady state aggregate consumption at time $t+z$.

6 However if $\alpha^{b}$ is increased in line with the minimal requirements of fiscal solvency as the survival probability is reduced, then the stabilising effect on consumption volatility of increasing the degree of non-Ricardian behaviour dominates the procyclical effect of a 'tougher' fiscal rule. 
Table 3

Average consumer. $\psi \times 10^{3}$

\begin{tabular}{|c|c|c|c|c|c|c|}
\hline \multirow[b]{3}{*}{$\gamma$} & \multicolumn{6}{|c|}{$b / y$} \\
\hline & \multicolumn{2}{|c|}{1.0} & \multicolumn{2}{|c|}{2.5} & \multicolumn{2}{|c|}{4.0} \\
\hline & $\psi^{d}$ & $\psi^{l}$ & $\psi^{d}$ & $\psi^{l}$ & $\psi^{d}$ & $\psi^{l}$ \\
\hline 0.990 & 0.31 & 0.29 & 0.29 & 0.27 & 0.28 & 0.26 \\
\hline 0.970 & 0.23 & 0.21 & 0.19 & 0.17 & 0.17 & 0.15 \\
\hline 0.950 & 0.17 & 0.15 & 0.13 & 0.12 & 0.11 & 0.10 \\
\hline
\end{tabular}

Since the above expression can be written as,

$$
\begin{aligned}
0= & \sum_{z=0}^{\infty}(\gamma \beta)^{z}\left\{\ln (1-\psi) \bar{c}_{t+z}+\chi \ln \bar{m}_{t+z}+\varkappa \ln \left(1-\bar{l}_{t+z}\right)\right\} \\
& -\sum_{z=0}^{\infty}(\gamma \beta)^{z}\left\{\begin{array}{c}
\ln \left(1+\widehat{c}_{t+z}\right) \bar{c}_{t+z}+\chi \ln \left(1+\widehat{m}_{t+z}\right) \bar{m}_{t+z} \\
+\varkappa \ln \left(1-\bar{l}_{t+z}\right)\left(1-\frac{\bar{l}_{t+z}^{n}}{1-\widehat{l}_{t+z}^{n}} \widehat{l}_{t+z}\right)
\end{array}\right\}
\end{aligned}
$$

then

$\ln (1-\psi) \frac{1}{1-\gamma \beta}=\sum_{z=0}^{\infty}(\gamma \beta)^{z}\left\{\ln \left(1+\widehat{c}_{t+z}\right)+\chi \ln \left(1+\widehat{m}_{t+z}\right)+\varkappa \ln \left(1-\frac{\bar{l}_{t+z}}{1-\bar{l}_{t+z}} \widehat{l}_{t+z}\right)\right\}$

defines our measure of the welfare of different degrees of fiscal distortion. The proportion of steady-state consumption that the average consumer will pay to eliminate shocks in a lump-sum and distortionary economy is given in Table 3. The sensitivity of this relative welfare measure to changes in the ratio of government debt to GDP and the degree of non-Ricardian behaviour on the part of consumers is also detailed.

Consistently with the fact that volatilities are almost always higher in the economy with distortionary taxation, welfare is higher in the lump-sum economy. Even in the case in which fiscal stabilisers are capable of delivering lower consumption volatility, the welfare repercussions of higher real balances and labour volatilities under distortionary taxation dominate such that welfare cost of technology shocks are higher in the distortionary tax economy. Nevertheless, as the level of debt and probability of death are increased, the welfare costs of shocks fall regardless of the tax structure and the welfare differences across the two economies also falls. 


\section{Conclusions}

In this paper we have developed a New Keynesian model with overlapping generations of finitely-lived consumers such that government debt is part of net wealth. This extends the number of channels through which fiscal policy could affect real and nominal variables, as compared with standard models with Ricardian consumers. Households supply labour to imperfectly competitive firms who produce goods using this labour and physical capital. To introduce a non-trivial role for monetary policy, prices set by firms are sticky in the manner of Calvo (1983). Labour income, profits and consumption expenditure are all subject to distortionary taxation, such that consumption, labour supply, pricing and investment decisions are all affected by taxation. The government also spends resources in consumption transfers and productive expenditures which affect productivity. As a result the description of fiscal policy within our economy is very rich. We then calibrate the model to capture the main business cycle stylised facts for the European economies and assess the role of automatic stabilisers in affecting the volatility of the key components of aggregate demand.

We find that, the presence of finitely-lived households increases the automatic stabilization of distortionary taxes through the reduction of the volatility of consumption in the face of technology shocks, but at the cost of increasing the volatility of investment and labour supply. The net impact on volatility depends crucially on the size of the outstanding stock of government debt and the extent to which consumer behaviour is non-Ricardian. Typically, such a wealth effect will tend to reduce consumption variability, with repercussions for movements in labour supply. However, when the outstanding stock of debt is relatively high, then the volatility in investment expenditures in the presence of distortionary taxation is so great that it dominates the stabilising impact on consumption. We then draw out the welfare implications of this analysis, by looking at the utility of the average consumer. We find that, in general the welfare cost of fluctuations is higher when distortionary taxes are present and, therefore, the reduction in the relative volatility of consumption does not compensate for the high volatility of labour supply and real balances. However, as the wealth effect of government debt increases (either through less Ricardian behaviour on the part of consumers or increases in the steady-state debt to GDP ratio), then the welfare costs of shocks decrease and the difference between a lump-sum and distortionary-taxation financed economy is less marked.

\section{References}

Agresti, A. M. and B. Mojon (2001): "Some Stylised Facts on the Euro Area Business Cycle". ECB Working Paper No. 95. 
Andrés, J. and R. Doménech (2003): "Automatic Stabilizers, Fiscal Rules and Macroeconomic Stability". Mimeo. Universidad de Valencia. (Available at http://iei.uv.es/ rdomenec).

Benassy, J-P. (2003): "Fiscal Policy and Optimal Monetary Policy Rules in a non-Ricardian Economy". Review of Economic Dynamics, 6, pp 498-512.

Benigno, P. and M. Woodford (2003): "Optimal Targeting Rules for Monetary and Fiscal Policy". Mimeo. New York University.

Blanchard, O. and R. Perotti (2002): "An Empirical Characterization of the Dynamic Effects of Changes in Government Spending and Taxes on Output". Quarterly Journal of Economics, 1329-68.

Calvo, G. (1983): "Staggered Prices in a Utility Maximizing Framework". Journal of Monetary Economics, 12(3), 383-98.

Clarida, R., J.Galí and M. Gertler (1999): "The Science of Monetary Policy: A New-Keynesian Perspective". Journal of Economic Literature, 37, 1661-1707.

Fatas, A., and I.Mihov (1998): "Measuring the Effects of Fiscal Policy". Mimeo, INSEAD.

Galí, J. (1994): "Government Size and Macroeconomic Stability”. European Economic Review, 38(1), $117-132$.

Leeper, E. (1991): "Equilibria under 'Active' and 'Passive' Monetary and Fiscal Policies". Journal of Monetary Economics, 27, 129-147.

Leith, C. and S. Wren-Lewis (2000): "Interactions between Monetary and Fiscal Policy Rules". The Economic Journal, 110, 93-108.

Schmitt-Grohé, S. and M. Uribe (1997): "Balanced-Budget Rules, Distortionary Taxes and Aggregate Instability". Journal of Political Economy, 105 (5), 976-1000.

Schmitt-Grohé, S. and M. Uribe (2002): "Optimal Fiscal and Monetary Policy Under Sticky Prices". NBER Working Paper No. w9220.

Woodford, M. (1996): "Control of the Public Debt: A Requirement for Price Stability?". NBER Working Paper no. 5684. 